\title{
Solar cycle and seasonal variations of the GPS phase scintillation at high latitudes
}

\author{
Yaqi Jin ${ }^{1}{ }^{*}$, Wojciech J. Miloch ${ }^{1}$, Jøran I. Moen ${ }^{1,2}$, and Lasse B.N. Clausen ${ }^{1}$ \\ 1 Department of Physics, University of Oslo, PO Box 1048, Blindern, 0316 Oslo, Norway \\ 2 Arctic Geophysics, University Centre in Svalbard, 9171 Longyearbyen, Norway
}

Received 18 September 2017 / Accepted 5 September 2018

\begin{abstract}
We present the long-term statistics of the GPS phase scintillation in the polar region $\left(70^{\circ}-82^{\circ}\right.$ magnetic latitude) by using the GPS scintillation data from Ny-Ålesund for the period 2010-2017. Ny-Ålesund is ideally located to observe GPS scintillations modulated by the ionosphere cusp dynamics. The results show clear solar cycle and seasonal variations, with the GPS scintillation occurrence rate being much higher during solar maximum than during solar minimum. The seasonal variations show that scintillation occurrence rate is low during summer and high during winter. The highest scintillation occurrence rate is around magnetic noon except for December 2014 (solar maximum) when the nightside scintillation occurrence rate exceeds the dayside one. In summer, the dayside scintillation region is weak and there is a lack of scintillations in the nightside polar cap. The most intriguing features of the seasonal variations are local minima in the scintillation occurrence rate around winter solstices. They correspond to local minima in the F2 peak electron density. The dayside scintillation region migrates equatorward from summer to winter and retreats poleward from winter to summer repetitively in a magnetic latitude range of $74^{\circ}-80^{\circ}$. This latitudinal movement is likely due to the motion of the cusp location due to the tilt of the Earth's magnetic field and the impact of the sunlight.
\end{abstract}

Keywords: GPS scintillation / space weather / seasonal variation / solar cycle / polar cap patches

\section{Introduction}

Our modern society can be highly affected by space weather. One of the most important space weather effects is the scintillation of trans-ionospheric radio signals. Ionospheric scintillation can strongly degrade the satellite based communication and navigation systems. When a satellite signal passes through irregularities in the ionosphere, the signal received on the ground exhibits random fluctuations in both amplitude and phase. These fluctuations are referred to as amplitude and phase scintillations, respectively (e.g. Yeh \& Liu, 1982; Kintner et al., 2007 and references therein).

The phenomenon of ionospheric scintillation was reported as early as in 1946 (Hey et al., 1946), and it has been extensively studied since the launch of artificial satellites. Early studies using VHF/UHF signals revealed the global morphology of ionospheric scintillations, namely that the scintillations are frequently observed near the magnetic equator and at high latitudes (Aarons, 1982; Rino et al., 1983; Basu et al., 2002;

\footnotetext{
${ }^{*}$ Corresponding author: yaqi.jin@fys.uio.no
}

Wernik et al., 2003). In this paper we address the ionospheric scintillation at high latitudes.

Since the beginning of the GPS era, there have been many studies of the ionospheric scintillation at high latitudes based on the GPS signal. Some studies focused on specific ionospheric phenomena such as polar cap patches (Mitchell et al., 2005; Jin et al., 2014, 2016; van der Meeren et al., 2014; Wang et al., 2016), auroral blobs on the nightside (Jin et al., 2014, 2016), the dayside cusp aurora with Poleward Moving Auroral Forms (PMAFs) (Jin et al., 2015; Oksavik et al., 2015), periods of enhanced dayside and nightside reconnection (Clausen et al., 2016), cusp dynamics in association with the production of polar cap patches when solar EUV ionized plasma is entrained into the polar cap (Jin et al., 2017), and hot patches in the polar cap (Zhang et al., 2017). Other studies focused on the statistical scintillation climatology maps (e.g. Spogli et al., 2009; Alfonsi et al., 2011; Prikryl et al, 2011, 2015), and their response to the solar flares (Priyadarshi et al., 2016) and solar wind variations (corotating interaction regions or interplanetary coronal mass ejections, e.g. Prikryl et al., 2012). Both global and local studies contribute towards 
a better understanding of the scintillating structures and the forecasting of the ionospheric scintillation activity.

The ionospheric scintillation exhibits considerable variability in space and time, which depends on many factors, such as latitude, local time, season, solar and magnetic activity (Basu et al., 2002; Wernik et al., 2003). Although GPS scintillations at high latitudes have been studied for more than three decades (Weber et al., 1986; Basu et al., 1988; Aarons et al., 2000; Mitchell et al., 2005; Spogli et al., 2009; Prikryl et al., 2010; Jin et al., 2014), there is no study that demonstrates the solar cycle dependence of GPS scintillations in the Polar Regions.

Prior to the GPS era, the solar activity dependence of ionospheric scintillations was studied by Aarons et al. (1981) and Basu et al. (1988); they investigated the amplitude scintillation using a satellite beacon at $250 \mathrm{MHz}$ at Thule. However, those studies used a much lower frequency than the GPS signal. As a result, the intensity fades due to amplitude scintillations are more frequent at $250 \mathrm{MHz}$ than those at $\mathrm{GHz}$ for the GPS signals. Furthermore, Thule is a station located in the polar cap $\left(83^{\circ}\right.$ magnetic latitude (MLAT)), where the diurnal variation of the scintillation data from a single satellite is virtually absent (Basu et al., 1987). Nowadays, the GPS scintillation data, with up to 12 GPS satellites available simultaneously, allow for a much larger spatial coverage. Therefore, it is possible to study the diurnal and spatial variations of the scintillation activity and their dependence on the solar cycle as well as to increase our understanding of the high latitude ionospheric scintillation.

The seasonal variations of GPS phase scintillations at high latitudes have been reported to show a high scintillation activity in winter and low activity in summer (e.g. Li et al., 2010; Prikryl et al., 2015). In the present study we expand the time period including both solar minimum and solar maximum to reveal some new features of the GPS phase scintillation at high latitudes. We find an unexpected drop in the scintillation activity close to winter solstices and we relate this decrease of the ambient electron density.

The main purpose of this study is to explore the long-term statistics (the solar cycle and seasonal variations) of the GPS phase scintillations in the polar ionosphere (above $70^{\circ}$ MLAT) and identify factors, which control the scintillation activity, with emphasis on the impact of the sunlight. It should be noted that the GPS scintillation data have been recorded at Ny-Ålesund, Svalbard, i.e. in the European Arctic Sector. Svalbard is a particular ideal location to study the daytime cusp auroral dynamics and production of polar cap patches around magnetic noon (Sandholt et al., 1998; Moen et al., 2001a, 2008). During magnetic substorms, polar cap patches exiting the polar cap into the auroral oval can be observed around magnetic midnight (Lorentzen et al., 2004; Moen et al., 2007, 2015; Jin et al., 2014).

\section{Instrumentation and data description}

In this study, we use data from one GPS scintillation receiver and a dynasonde in Svalbard. Furthermore, the solar sunspot number and the hourly OMNI solar wind data (interplanetary magnetic field (IMF) and solar wind velocity) are used to assist the data analysis.

\subsection{The GPS scintillation receiver}

The GPS scintillation receiver has been operated on the roof of the Sverdrup Research Station at Ny-Ålesund, Svalbard $\left(78.9^{\circ} \mathrm{N}, 11.9^{\circ} \mathrm{E} ; 76.6^{\circ} \mathrm{MLAT}\right)$ by the University of Oslo since December, 2009. The receiver is the standard GPS Ionospheric Scintillation/Total Electron Content (TEC) Monitor (GISTM), model GSV4004 (Van Dierendonck et al., 1993). The GISTM can compute and record the amplitude $\left(S_{4}\right)$ and phase scintillation indices $\left(\sigma_{\phi}\right)$ over 1 min intervals based on $50 \mathrm{~Hz}$ measurements of the received power and carrier phase at the GPS L1 frequency (1.57542 GHz). We use an elevation cutoff angle of $20^{\circ}$ to minimize the multi-path effect, which is enough for the GPS data from Ny-Ålesund (e.g. Spogli et al., 2009; Jin et al., 2015). The vertical phase scintillation index $\left(\sigma_{\phi}\right)$ can be calculated from the slant phase scintillation index $\tilde{\sigma_{\phi}}(\mathrm{el})$ at a certain elevation angle (el) using the following formula (e.g. Alfonsi et al., 2013; Spogli et al., 2013; Rino, 1979):

$$
\sigma_{\phi}=\tilde{\sigma_{\phi}}(\mathrm{el}) \times(F(\mathrm{el}))^{a}
$$

where $F(\mathrm{el})$ is the obliquity factor defined as:

$$
F(\mathrm{el})=\sqrt{1-\left(\frac{R_{\mathrm{E}} \cos (\mathrm{el})}{R_{\mathrm{E}}+H_{\mathrm{IPP}}}\right)^{2}}
$$

where $R_{\mathrm{E}}$ is the Earth radius and $H_{\mathrm{IPP}}$ is the height of the Ionospheric pierce point $(350 \mathrm{~km}$ in this study). The exponent $a$ is assumed to be 0.5 (Spogli et al., 2009).

\subsection{The ESR dynasonde}

To present the background ionospheric condition, we choose to use the $\mathrm{NmF} 2$ data from the dynasonde that was located near the European Incoherent SCATter (EISCAT) Svalbard Radar (ESR) site at Longyearbyen, Svalbard $\left(78.15^{\circ} \mathrm{N}, 16.02^{\circ} \mathrm{E}\right.$; $75.4^{\circ}$ MLAT). The dynasonde was operated from September 2009 until it was decommissioned in June 2015. In contrast to the ESR, which is only operated occasionally, the dynasonde was operated continuously and the data were routinely available. For this reason, the dynasonde data are particularly useful in the present study, which focuses on the long-term behavior of the ionosphere. The dynasonde measured, among other parameters, the F2 layer critical frequency (foF2) (e.g. Zabotin et al., 2006; Rietveld et al., 2008). The temporal resolution of foF2 varied from $2 \mathrm{~min}$ to $6 \mathrm{~min}$ during the operation. The temporal resolution was generally $6 \mathrm{~min}$ from January 2010 to November 2013, and it was 2 min afterwards.

The $\mathrm{F}$ region peak electron density $(\mathrm{NmF} 2)$ can be obtained from the critical frequency as follows (see e.g. Breed \& Goodwin, 1997):

$$
\mathrm{NmF} 2=1.24 \times 10^{10}(\mathrm{foF} 2)^{2}
$$

where foF2 is the F2 layer critical frequency in $\mathrm{MHz}$, and $\mathrm{NmF} 2$ is in unit of $\mathrm{m}^{-3}$. Due to questionable data quality by the end of the dynasonde's commission phase, we only use the NmF2 data from January 2010 to May 2015.

\subsection{The sunspot number and hourly OMNI solar wind data}

Since we present the ionospheric data from different phases of the solar cycle, it will be instructive to use the sunspot 


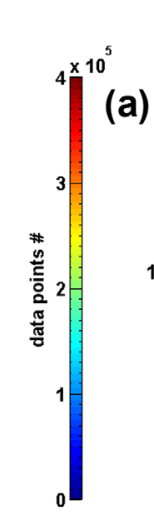

Year $=2010-2017$

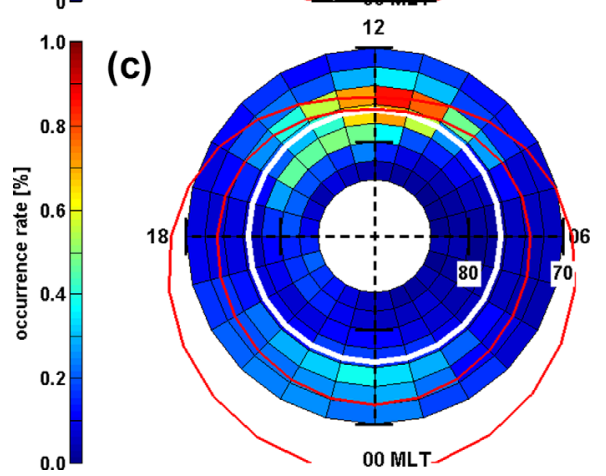

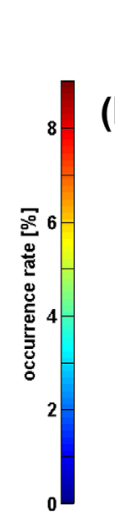
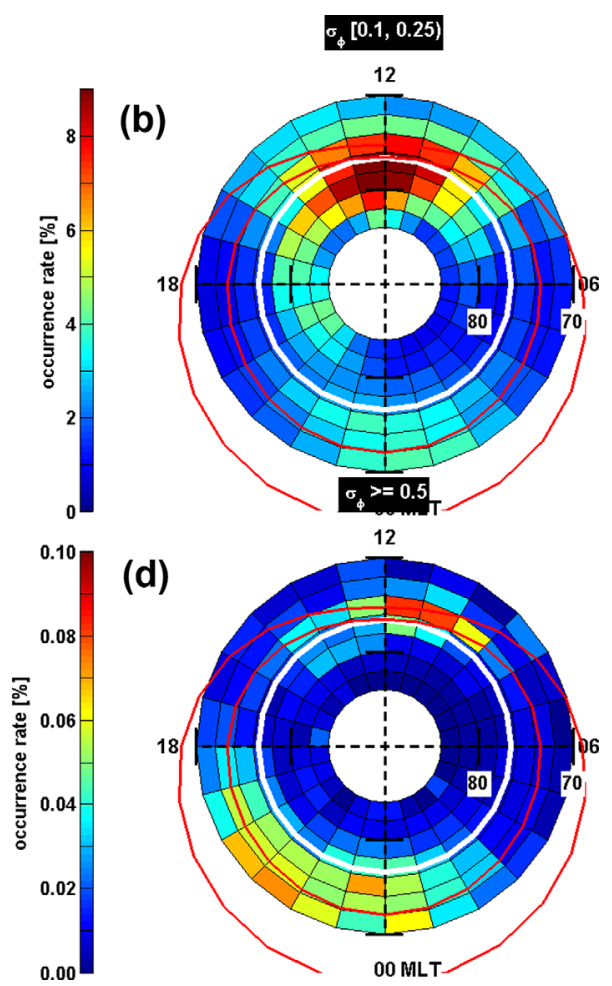

(d)

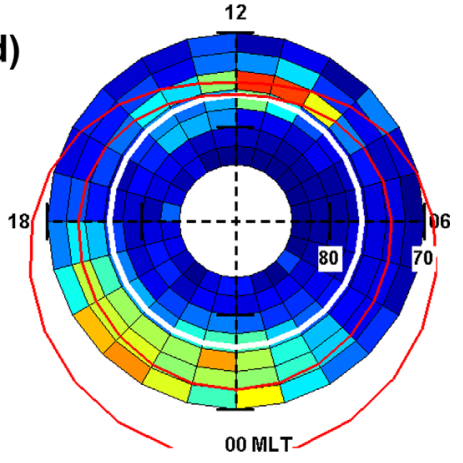

Fig. 1. The climatology map of the GPS phase scintillations for all observations from January 2010 to December 2017 from Ny-Ålesund in MLAT and MLT coordinates. The data are divided into bins defined by $1 \mathrm{~h}$ in MLT and by $2^{\circ}$ in MLAT. The Feldstein auroral oval (IQ $=3$ ) is plotted in each panel by red lines. The MLAT $\left(76.6^{\circ}\right)$ of Ny-Ålesund is shown by a thick white circle. (a) The number of data points in each bin. The occurrence rate for weak (b), intermediate (c), and strong (d) GPS phase scintillations.

number as an indication of the solar activity and the solar cycle. We use the monthly sunspot data from the World Data Center SILSO, Royal Observatory of Belgium, Brussels. The sunspot number is often used as an indicator of the solar activity and in particular, to monitor the solar cycle variation (e.g. Hathaway, 2015).

Since the status of the polar ionosphere is strongly affected by the solar wind and IMF conditions via the solar windmagnetosphere-ionosphere coupling, we use the Kan-Lee electric field $\left(E_{\mathrm{KL}}=V \times \mathrm{B}_{T} \times \sin ^{2}\left(\theta_{\mathrm{c}} / 2\right)\right)$ as the solar windmagnetosphere-ionosphere coupling function to monitor the long-term solar wind forcing (Kan \& Lee, 1979). In the formula of $E_{\mathrm{KL}}, V$ and $\mathrm{B}_{\mathrm{T}}$ are the hourly solar wind speed and IMF strength, respectively, and $\theta_{\mathrm{c}}$ is the IMF clock angle. The clock angle $\left(\theta_{\mathrm{c}}\right)$ is defined as the angle between the $Z$-axis and the projection of the IMF vector onto the $Y-Z$ plane of the geocentric solar magnetospheric (GSM) coordinate system $\left(\theta_{\mathrm{c}}=\arctan \left(\frac{B y}{B z}\right)\right)$. The IMF and solar wind data are taken from the hourly OMNI data set (King \& Papitashvili, 2005).

\section{Results and discussion}

\subsection{GPS phase scintillation climatology}

To provide the context for the study and present the field of view, we show in Figure 1 the climatology map of the GPS phase scintillations. The GPS data are obtained from the Ny-Ålesund station from January 2010 to December 2017.
The ionospheric piercing points are projected onto the altitude of $350 \mathrm{~km}$. The GPS data are divided into bins defined by 1 hour magnetic local time (MLT) and by $2^{\circ}$ MLAT. In addition, the Feldstein auroral oval (IQ $=3$ for moderate geomagnetic activity) is also plotted to indicate the location of the auroral region (Holzworth \& Meng, 1975).

Figure 1a shows the number of data points in each bin. One can see that the number of data points is highest (up to $3.8 \times 10^{5}$ ) in bins between $74^{\circ}$ and $76^{\circ}$ MLAT. To make a good statistics, we only show bins with more than $4 \times 10^{4}$ data points.

Figure $1 b-d$ shows the occurrence rates of weak $(0.1-0.25 \mathrm{rad})$, moderate $(0.25-0.5 \mathrm{rad})$, and strong $(>0.5 \mathrm{rad})$ GPS phase scintillations. The scintillation occurrence rate is defined as $100 \times N\left(\sigma_{\phi}\right) / N_{\text {tot }}$, where $N\left(\sigma_{\phi}\right)$ is the number of data points, for which the phase scintillation index is within a certain range of values (i.e. $0.1-0.25,0.25-0.5,>0.5 \mathrm{rad}$ ) and $N_{\text {tot }}$ is the total number of data points in the bin. When comparing with the Feldstein auroral oval, the field of view of our data covers the cusp region on the dayside around magnetic noon, while at night during normal conditions it covers the polar cap and a small part of the nightside auroral oval.

Figure 1b shows that weak GPS phase scintillations are most frequent around magnetic noon near the nominal cusp $\left(\sim 76^{\circ}\right.$ MLAT). Jin et al. (2015) showed that the GPS phase scintillations on the dayside are closely collocated with the cusp region, independent of the scintillation strength and IMF orientation. The spread of the dayside scintillation region is likely due to the dynamic variation of the cusp location due 
to changing IMF and solar wind conditions (Newell et al., 1989) and due to the balance between the dayside and nightside reconnections (Moen et al., 2004; Lockwood et al., 2005). The region with the enhanced dayside scintillation occurrence rate also extends to the postnoon polar cap around $80^{\circ}$ MLAT. Besides, the scintillation occurrence also shows a slight enhancement around the magnetic midnight below $76^{\circ}$ MLAT. However, the occurrence rate of weak scintillations is much higher around noon than those around midnight. As the GPS phase scintillation level increases (Fig. 1c-d), the dayside scintillation region moves equatorward and shrinks in size, while the nightside scintillation region expands in size and becomes more dominant around pre-midnight. Figure 1d shows that the area of the nightside scintillation region is larger than the dayside one and the occurrence rate becomes comparable with the corresponding dayside region. It should be noted that the scintillation distribution around midnight resembles the distribution of polar cap patches exiting the polar cap into the nightside auroral oval (Moen et al., 2007, 2015). This feature has been addressed by Jin et al. $(2014,2016)$ and van der Meeren et al. (2015), and it was found that the GPS phase scintillation level is significantly enhanced when the polar cap patches exit into the nightside auroral oval.

The scintillation climatology in Figure 1 reveals a region of frequent scintillation occurrence near the magnetic noon at the footprint of magnetospheric cusp (see e.g. Spogli et al., 2009; Prikryl et al., 2011; Jin et al., 2015). The cusp ionosphere is recognized as an active region with structured electric fields, soft particle precipitation, large plasma flows, and intense auroral dynamics due to the dynamical coupling within the solar wind-magnetosphere-ionosphere system (e.g. Carlson, 2012; Moen et al., 2013 and references therein). It plays an important role in the formation of large-scale ionization structures, i.e., polar cap patches (see e.g. Moen et al., 2006; Zhang et al., 2013). Basu and coauthors were the first to study plasma structuring and scintillation under the influence of the dayside cusp aurora using ground-based instruments (e.g. Basu et al., 1998). Both Gradient Drift Instability (GDI) and Kelvin-Holmholtz Instability (KHI) have been proposed to explain the plasma structuring (e.g. Basu et al., 1990, 1991). The GDI works when the electron density gradient is parallel to the drift velocity of a plasma patch, while the KHI is operative when a velocity shear is present and the irregularities can be created around boundaries of velocity shears, independent of the shear direction (Keskinen \& Ossakow, 1983; Keskinen et al., 1988). These two instabilities have recently been investigated by using radars and in-situ measurement (see e.g. Carlson, 2012; Moen et al., 2012; Oksavik et al., 2011, 2012; Spicher et al., 2015). The dayside cusp often acts as a hard target for coherent scatter HF radars, i.e., the HF radars observe the collocation of the HF scatter and the cusp aurora (Milan et al., 1998; Moen et al., 2001b). This indicates that there exist electron density irregularities at decameter scale in cusp auroral region which can backscatter the HF signal. In order to explain the cusp HF backscatter irregularities, Moen et al. (2002) quantified the growth rate of the GDI by using ionospheric tomography and radar data. By using the high-resolution in-situ data from a sounding rocket, Moen et al. (2012) demonstrated that GDI is indeed operative in the cusp ionosphere on time scale of one minute. Frequent observations of mesoscale flow shears in the cusp ionosphere indicate that the $\mathrm{KHI}$ is also a candidate in creating plasma irregularities (Oksavik et al., 2004, 2005; Rinne et al., 2007). This led Carlson and coauthors to propose a two-step process to explain the rapid onset of plasma irregularities in the cusp ionosphere, where the KHI first rapidly structures the entering plasma, after which the GDI works on large-scale structures created by the KHI, and produces smaller scale irregularities (Carlson et al., 2007, 2008). Jin et al. (2017) presented a case study in which two close points $(\sim 110 \mathrm{~km}$ apart) observed obvious different TEC gradients. This indicates that flow shears in the cusp ionosphere play a role in initializing the plasma structures. Therefore, both GDI and KHI need to be regarded as generators for GPS scintillations in the dayside cusp ionosphere (Jin et al., 2015, 2017; Oksavik et al., 2015). In addition to the plasma instability processes, the structured particle precipitation may create several $\mathrm{km}$ scale density gradients, and consequently the GDI can work on these density gradients to produce smaller scale irregularities (Moen et al., 2012). Thus the structured particle precipitation may initialize GPS scintillations in the dayside cusp region as well (Kelley et al., 1982; Moen et al., 2002, 2012; Jin et al., 2015; Oksavik et al., 2015).

\subsection{The solar cycle variation of GPS phase scintillations}

Having presented the scintillation climatology map as a context of the present study, we now show the diurnal and seasonal variations of the GPS phase scintillation. Since we use GPS data from January 2010 to December 2017, i.e., data from different phases of the solar cycle, we present the monthly sunspot number in Figure $2 \mathrm{a}$ as a measure of the solar activity and a guidance for the solar cycle. The sunspot number was very low until the end of year 2010, while it increased very rapidly in 2011 and reached a relative maximum (139 sunspots) in November 2011. A second abrupt increase of the sunspot number happened after the autumn equinox of 2013 and reached a maximum (146 sunspots) in February 2014. Then the monthly sunspot number remained above 100 until the beginning of 2015, after which it gradually decreased. The solar cycle 24 started in 2008 and remained at its minimal activity in 2010. As our GPS scintillation data started in 2010, we use year 2010 as the representative for the solar minimum condition, and we take year 2014 as the solar maximum condition.

We divide the GPS scintillation data into bins defined by $1 \mathrm{~h}$ MLT and by one month in time and show the GPS phase scintillation occurrence rate in Figure $2 b$. This is equivalent to integrating the monthly climatology maps along MLAT.

Not surprisingly, the long-term statistics of the GPS phase scintillation at high latitudes reflects the solar activity, i.e., the high scintillation activity in the winters of 2013-2014 and 2014-2015 was well connected to the high solar activity as indicated by the monthly sunspot number in Figure $2 \mathrm{a}$. Figure $2 \mathrm{~b}$ shows a high scintillation occurrence rate during the period 2014-2015 which is during the solar maximum in solar cycle 24 . It is also interesting to note that the scintillation occurrence rate is most prominent at the beginning of the declining phase of the solar cycle, which is similar to the occurrences of geomagnetic storms (Tsurutani et al., 2006). 


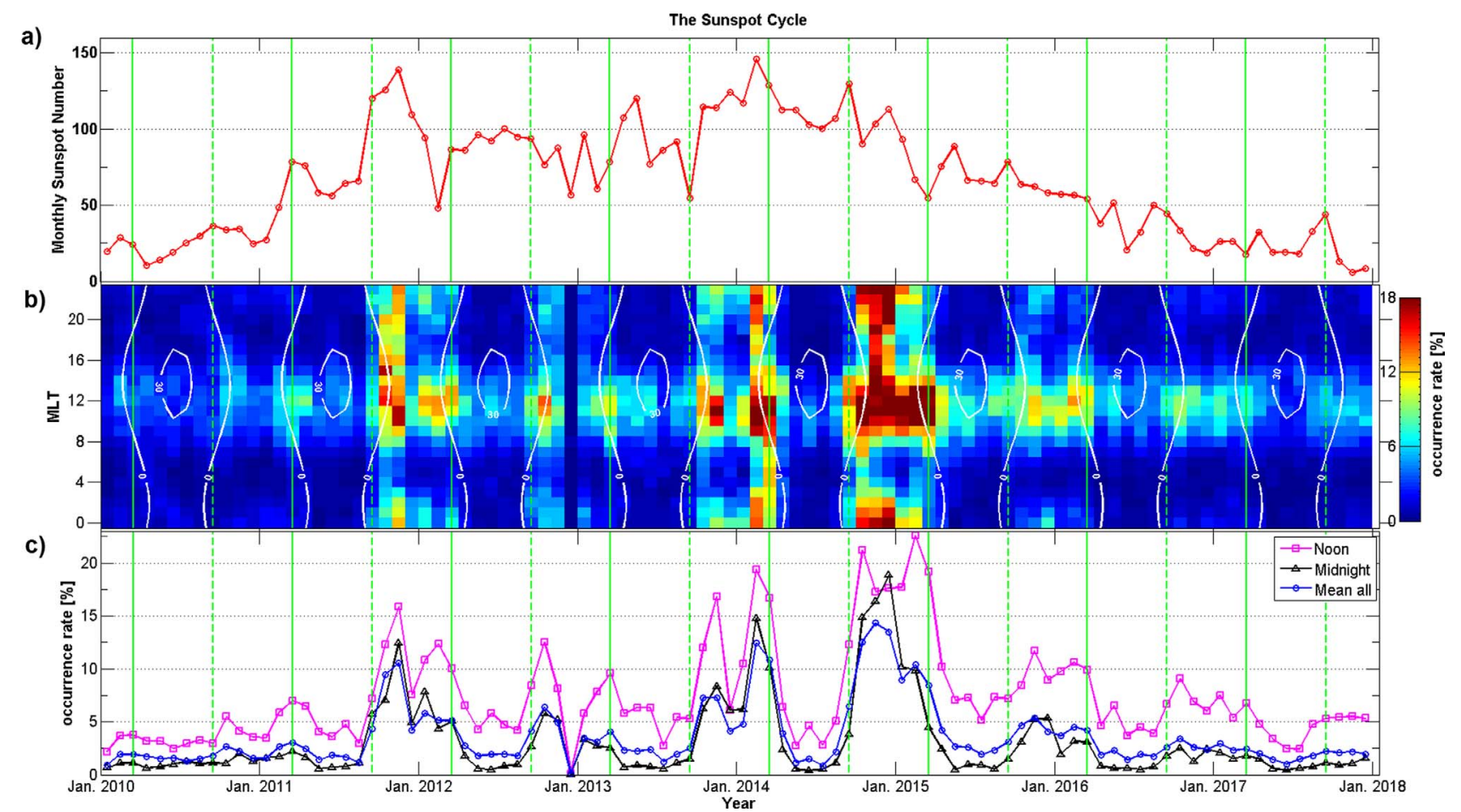

Fig. 2. (a) The monthly sunspot number. (b) The GPS phase scintillation occurrence rate $\left(\sigma_{\phi} \geq 0.1 \mathrm{rad}\right)$ as a function of MLT and month of year. The solar elevation angles of $0^{\circ}$ and $30^{\circ}$ at $110 \mathrm{~km}$ altitude above Ny-Ålesund are shown in white curves. (c) The monthly GPS phase scintillation occurrence rate around noon (11-13 MLT, magenta), midnight (22-01 MLT, black), and averaged over all local times (blue). The green solid and dashed vertical lines present the spring and autumn equinoxes, respectively.

In Section 3.8, we will show the occurrence rate of the Kan-Lee electric field of larger than $2 \mathrm{mV} / \mathrm{m}$, which is also more prominent during the declining phase of the solar cycle. The scintillation occurrence rate is also clearly enhanced at the end of 2011 when the monthly sunspot number is high. The scintillation occurrence rate is low from 2010 to the autumn equinox of 2011 as well as after the spring equinox of 2016 when the solar activity is low.

To the authors' knowledge, there have been two studies so far on the solar activity dependence of the ionospheric scintillation at high latitudes (Aarons et al., 1981; Basu et al., 1988). Aarons et al. (1981) compared the amplitude scintillation data during two distinct periods: 1975 (low solar activity) and 1979 (high solar activity). The measurements were performed at Thule Air Base, Greenland from a satellite beacon at $250 \mathrm{MHz}$. They observed very high scintillation levels in 1979 and much lower levels in 1975, and they related this striking contrast to the variations of the $\mathrm{F}$ layer electron density during different solar activity. Basu et al. (1988) presented the occurrence of amplitude scintillation at $250 \mathrm{MHz}$ for the period 1979-1986, also by using data from Thule. They observed a clear solar cycle variation of the amplitude scintillation, where the amplitude scintillation occurrence decreased significantly from solar maximum (1979) to solar minimum (1986). It was noted that the scintillation occurrence decreased very abruptly when the sunspot number dropped from above 100 to below 100. In Figure 2, we also see a significant decrease by a factor of 4.5 , from $23 \%$ in solar maximum (2015) to about $5 \%$ (at the end of 2017).

\subsection{Seasonal variation of the GPS phase scintillations}

There is an evident seasonal variation of the GPS phase scintillations, with high scintillation occurrence rate during winter and low occurrence during summer. The active scintillation regions are generally confined between the autumn and spring equinoxes (dashed and solid vertical lines in Fig. 2). The solar elevation angles of $0^{\circ}$ and $30^{\circ}$ are presented with white curves in Figure $2 b$ to show the impact of the sunlight on the GPS phase scintillation occurrence rate. The observation is in darkness during winter and it is in sunlight during summer. It is clear that the low scintillation occurrence rate and the high solar elevation angle $\left(30^{\circ}\right)$ match very well.

The seasonal differences in the scintillation occurrence rate are most evident during the solar maximum (2014-2015), while the difference is much weaker during the solar minimum (e.g. in 2010). The winter scintillation occurrence rate is much reduced during solar minimum conditions; however, the scintillation occurrence rate is relatively unchanged in the summer periods (except for the high scintillation activity in the summer of 2015). This indicates that the solar cycle modulates the formation of the irregularity power, which produces scintillations, differently between summer and winter.

The most interesting and unexpected feature in Figure $2 b$ is the decrease of the scintillation occurrence rate around the winter solstice (December and/or January). The winter minimum in the scintillation occurrence rate is more pronounced when the monthly sunspot number is greater than 50 . This feature can also be seen in Figure 2c for the averaged scintillation 


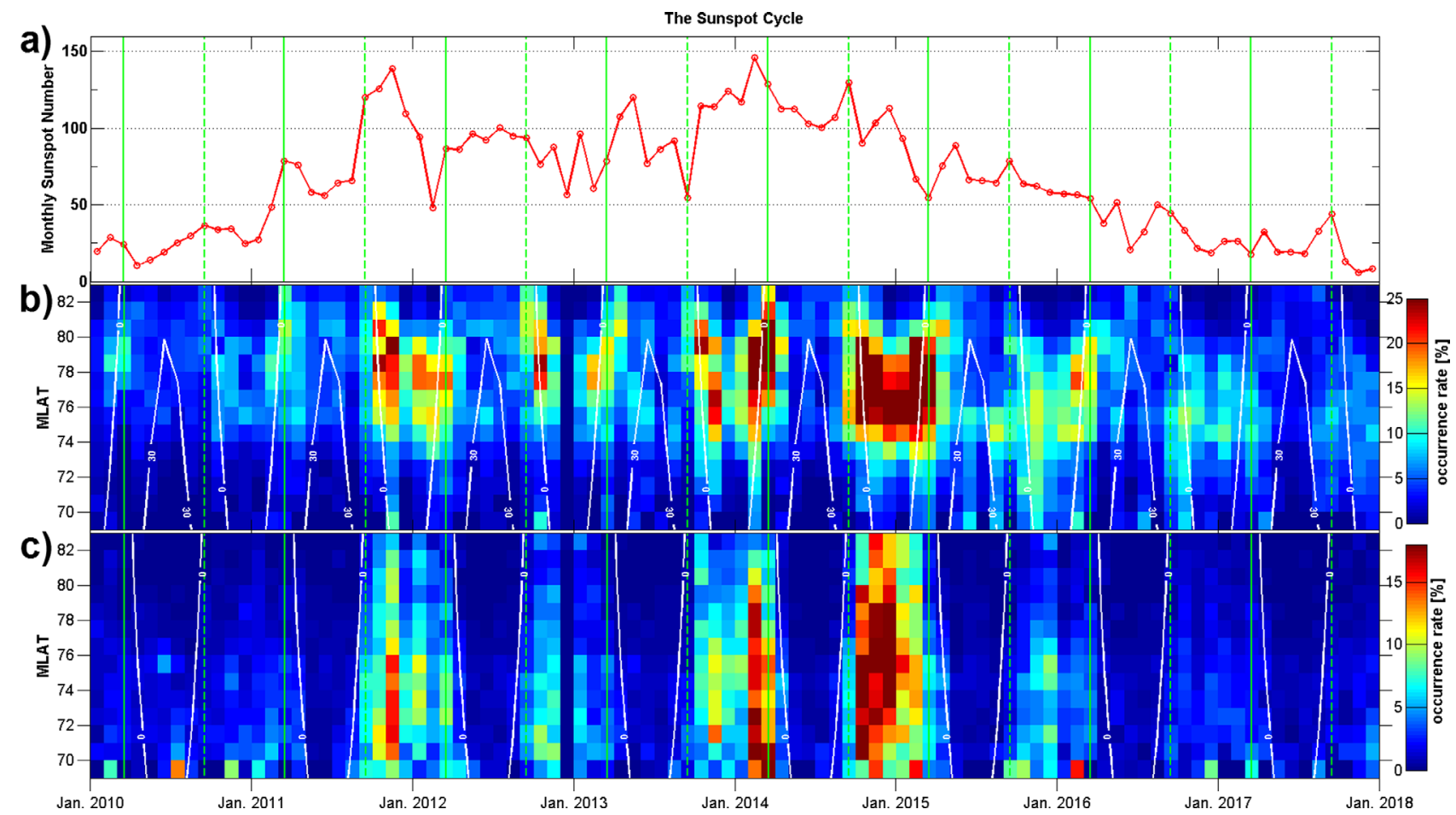

Fig. 3. (a) The monthly sunspot number (same as Fig. 2a). (b) The seasonal variations of the GPS phase scintillation occurrence rate around noon (10-14 MLT) and (c) around midnight (22-02 MLT) as a function of MLAT and month of year. The solar elevation angles of $0^{\circ}$ and $30^{\circ}$ at $110 \mathrm{~km}$ altitude above Ny-Ålesund are shown in white curves. Note that the color scales are different in panels b and c. The green solid and dashed vertical lines present the spring and autumn equinoxes, respectively.

occurrence rate (blue) and it is particularly clear for the noon time occurrence rate (magenta). This feature is also perceptible in the amplitude scintillation by Basu et al. (1988), but it has not been noticed nor reported before.

\subsection{Diurnal variation of the GPS phase scintillations}

The climatology map (Fig. 1) revealed that the scintillation occurrence rate peaks around the magnetic noon and midnight. Thus, in Figure 2c, we show, as a function of time, the scintillation occurrence rate around the magnetic noon and midnight in magenta and black lines, respectively. As it was observed in Figure $1 b$, the scintillation occurrence rate is generally higher around the magnetic noon than at the nightside in the considered latitude (above $70^{\circ}$ MLAT).

The same feature is particularly clear in Figure 2c during the solar minimum summer condition. As the solar activity increases, the winter scintillation occurrence rate around magnetic midnight becomes comparable to those around the magnetic noon. For example, during October and November, 2011 and October to December, 2014, the nightside scintillation occurrence rate increased significantly to become comparable to that on the dayside. This implies that the nightside scintillations are more sensitive to the variation in the solar activity.

During summer, the scintillations are only present around magnetic noon. However, the cusp signature of the noon time scintillation becomes very faint. Besides the scintillation region near the nominal cusp, the scintillation at night is much reduced as compared to those during winter. There is often a lack of scintillations in the summer night. Since the GPS data recorded at Ny-Ålesund are mainly in the polar cap at night, this implies that there are only very limited irregularities in the nightside polar cap during summer for the period of the study.

\subsection{Latitudinal variation of GPS phase scintillations}

Next we show the seasonal variation of the GPS scintillations as a function of MLAT. Figure 3a shows the monthly sunspot number to again provide indication about the solar cycle. We further divide the scintillation occurrence rate around the magnetic noon and midnight and divide the scintillation data into bins defined by $1^{\circ}$ MLAT and by 1 month. Figure $3 b$ shows the scintillation occurrence rate for the interval 10-14 MLT as a function of MLAT and month. This is equivalent to averaging the monthly climatology maps over $4 \mathrm{~h}$ around magnetic noon (10-14 MLT). Similar to the data presented in Figure $2 b$, the scintillation occurrence rate is highest during winter. The regions of high scintillation occurrence during winter are well defined in MLAT $\left(74^{\circ}-80^{\circ}\right)$ as compared to the weak scintillation signature during summer. An interesting feature is that the regions of high scintillation occurrence rate move equatorward from autumn equinoxes to winter solstices and retreat poleward from winter solstices to spring equinoxes. This pattern was repetitive from one year to another. The MLAT range varies from $80^{\circ}$ around equinoxes to $74^{\circ}$ around winter solstices and it does not change with the solar cycle.

Jin et al. (2015) showed that the GPS phase scintillation on the dayside is collocated with the cusp aurora. If we consider 
the dayside scintillation region as a proxy of the cusp location, the equatorward motion of the scintillation region indicates the equatorward migration of the cusp location from autumn to winter. The cusp location is very variable and strongly depends on the solar wind and IMF conditions as well as the balance between the dayside and nightside reconnections (see e.g. Newell et al., 1989, 2006; Moen et al., 2004; Lockwood et al., 2005, and references therein). Furthermore, the cusp location also varies with the Earth's dipole tilt angle (and hence with the season). Newell \& Meng (1989) studied the latitude of the cusp location using DMSP satellites and found a latitudinal difference of $4^{\circ}$ between summer (higher latitude) and winter (lower latitude). This can partly explain the equatorward migration of the statistical location of the scintillation region around noon.

Another contribution comes from the sunlight. The white curves in Figure $3 \mathrm{~b}$ present the solar elevation angles of $0^{\circ}$ and $30^{\circ}$. Figure $3 \mathrm{~b}$ shows that the solar elevation angle of $0^{\circ}$ moves equatorward from autumn equinoxes to winter solstices. The solar EUV produced E region is supposed to short-circuit the $F$ region irregularities and therefore reduce the scintillation occurrence rate (Kelley et al., 1982; Vickrey \& Kelley, 1982). As a result, the scintillations in the dark cusp are supposed to occur more frequently than those in the sunlit cusp. For the time periods away from the winter solstice, the scintillations in the dark cusp (which is at higher latitudes) contribute more to the statistics than those in the sunlit cusp (which is at lower latitudes). This can also explain the equatorward and poleward movements of the noon time scintillation region.

Figure $3 \mathrm{~b}$ shows that the solar elevation angle of $0^{\circ}$ confines the scintillation region in the dark ionosphere. However, the solar terminator related density gradients should not produce strong impact on the scintillation statistics. If the solar terminator related density gradients could produce significant scintillations, the scintillation regions should only be found near the solar terminator instead of being confined within the dark ionosphere. A second reason to exclude the solar terminator related density gradients is that the scintillation region only migrates equatorward to $74^{\circ}$ MLAT and it does not move further south, while the solar terminator moves to below $70^{\circ}$ MLAT during deep winter. However, there is indeed a weak sign of movement down to $\sim 70^{\circ}$ MLAT along with the solar terminator in November 2015 (seen in yellow color). These may be caused by the solar terminator related density gradients. However, further specific studies are needed to evaluate how effective the solar terminator related density gradients could contribute to the GPS phase scintillation.

Figure $3 c$ shows the corresponding statistics as Figure $3 b$ but for the night time (22-02 MLT). The scintillation occurrence rates are higher during the winters of 2011-2012, 2013-2014, and 2014-2015, however, there is no movement in the scintillation region. The solar elevation angle of $0^{\circ}$ clearly delimits regions of "scintillation holes" which are voids of GPS phase scintillations in the polar cap during the summer night. The lack of observed movement in the nightside scintillation region is probably due to the high latitude location of Ny-Ålesund. The auroral oval is normally south of the field of view at night. The aurora covers the field of view only during the poleward expansion of auroral oval during substorm (see e.g. Jin et al., 2016). The GPS data are mainly from the nightside polar cap where there is no well-defined scintillation region in contrast to those in the cusp region.

\subsection{NmF2}

In order to present the long-term variations of the background ionospheric condition, we present in Figure 4 the $\mathrm{NmF} 2$ data from the dynasonde at Longyearbyen (where magnetic noon is at $\sim 09$ UT). The monthly sunspot number is reproduced in Figure $4 \mathrm{a}$ as a guidance. The NmF2 data are divided into bins defined by 1 hour in UT and by 1 month. Note that the NmF2 data are from January 2010 to May 2015, whilst the scintillation data considered in previous subsections are from January 2010 to December 2017. The median value of $\mathrm{NmF} 2$ in each bin is displayed in Figure $4 \mathrm{~b}$. As expected, the background $\mathrm{F}$ region ionospheric density was high during solar maximum in 2014 and low during the solar minimum in 2010. The significant enhancements in NmF2 around March 2014 and October 2011 were associated with short-term increases of the solar activity (see e.g. Themens \& Jayachandran, 2016). The solar activity near March 2014 and October 2011 were similar, however, the NmF2 enhancement is more significant in March 2014. This is most probably due to the different solar elevation angles at Longyearbyen during these two time periods, as photo-ionization by the solar EUV radiation depends on the solar elevation (thus zenith) angle.

Similar to the mid-latitude ionosphere, the NmF2 at Longyearbyen shows clear semiannual variation, i.e., the $\mathrm{NmF} 2$ is higher at equinoxes than that at solstices (see e.g. Cai et al., 2008; Zou et al., 2000). The winter anomaly (that the noon time NmF2 is higher in winter than that in summer) is not present at this latitude (geographic latitude of $78^{\circ} \mathrm{N}$ ). On contrary, due to the lack of sunlight, the winter NmF2 is generally lower than that during summer at daytime.

During equinoxes, the NmF2 exhibits clear diurnal variation with the maximum density at daytime (magnetic noon and afternoon) and low density at night. However, the diurnal variation during winter time shows two peaks: around the magnetic noon and close to the magnetic midnight. This observation is similar to Moen et al. (2008) who reported two maxima in the NmF2 around 12 MLT and 23 MLT by using the ESR data in February 2001 and October 2002 (close to the solar maximum). They explained their observation by the transport of the EUV ionized plasma across the polar cap from the dayside to nightside ionosphere.

Figure $4 \mathrm{c}$ shows the monthly $\mathrm{NmF} 2$ data around the magnetic noon and midnight in magenta and black lines, respectively, whilst the blue line is averaged over all local times. The NmF2 increased from $1.3 \times 10^{11} \mathrm{~m}^{-3}$ in January 2010 to as high as $7.3 \times 10^{11} \mathrm{~m}^{-3}$ in March 2014 as the solar activity increased. During winter it is also clear that the dayside and nightside densities are comparable, and the nightside density exceeds the dayside ones occasionally.

Note that it is not straightforward to directly correlate the GPS scintillation data and the NmF2 from the dynasonde due to the following reasons: (1) the dynasonde can only probe the ionosphere in a narrow field-of-view of about $60^{\circ}$ (Alfonsi et al., 2013), whilst the GPS data show a significantly wider field-of-view (in this study, we use data with elevation angle above $20^{\circ}$ ); (2) the $\mathrm{NmF} 2$ data only give information about 


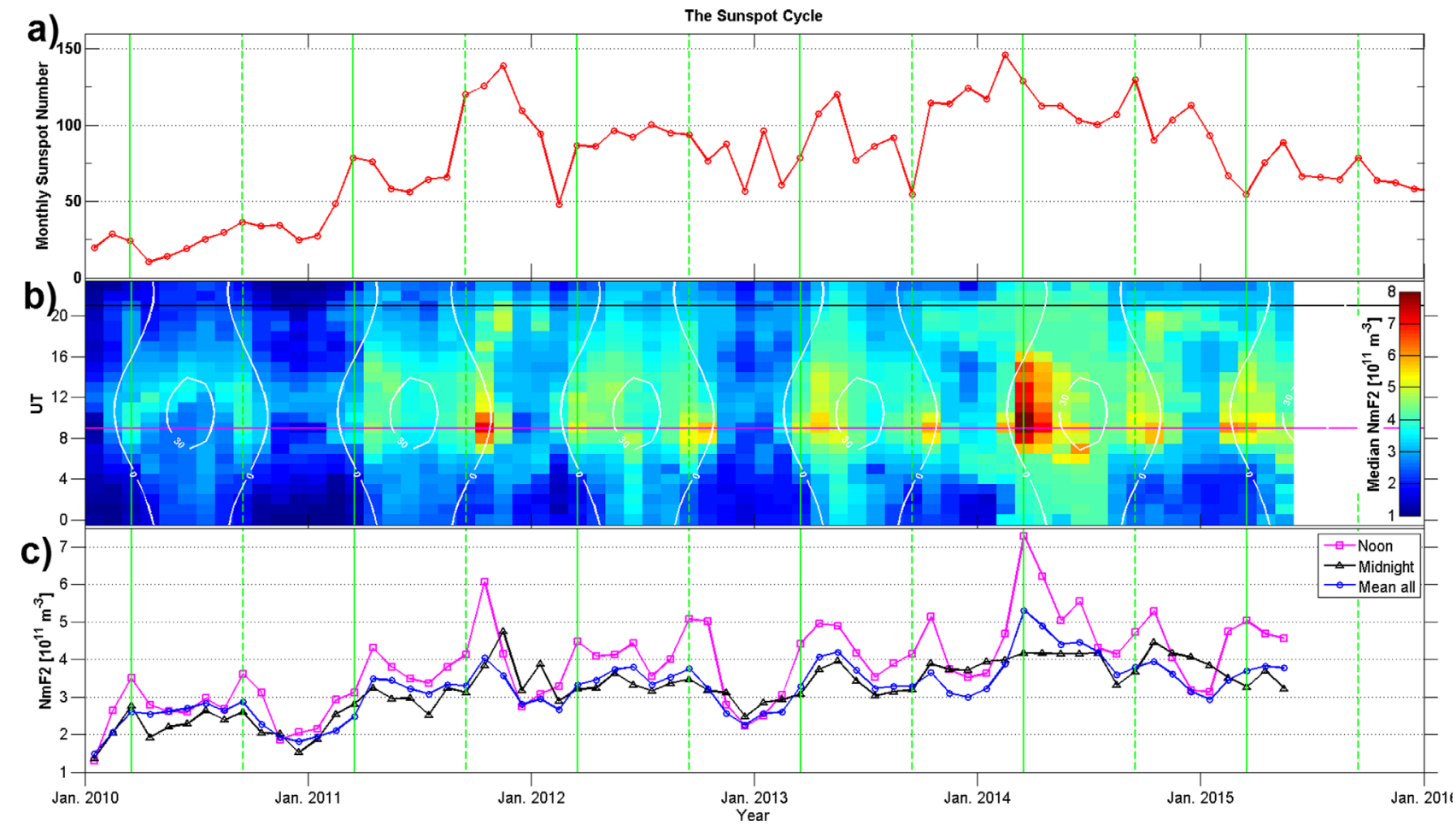

Fig. 4. (a) The monthly sunspot number (same as Fig. 2a). (b) The diurnal and seasonal variations of NmF2 from the Longyearbyen dynasonde as a function of UT and month of year. The magnetic noon and midnight are plotted in magenta and black horizontal lines, respectively. The green solid and dashed vertical lines present, respectively, the spring and autumn equinoxes. The solar elevation angles of $0^{\circ}$ and $30^{\circ}$ at $110 \mathrm{~km}$ altitude above Longyearbyen are overlaid by white curves. (c) The monthly NmF2 data around the magnetic noon (11-13 MLT, magenta), and magnetic midnight (22-01 MLT, black), as well as averaged over all local times (blue).

the F2 peak density, while the GPS scintillation can be affected by the plasma structures along the entire ray-path of the GPS receiver-satellite pair. However, in this study, we intend to use the NmF2 to present the temporal variations of the background electron density, and do not aim to study the exact relation between the GPS phase scintillation and the NmF2 data. With this in mind, we discuss the variability of the GPS phase scintillation climatology in the next subsection.

\subsection{The relation between NmF2 and the GPS phase scintillations}

The scintillation activity depends on the absolute fluctuations of the ionospheric electron density $(\Delta \mathrm{Ne})$ rather than on the relative density fluctuations $(\Delta \mathrm{Ne} / \mathrm{Ne})$ (Aarons et al., 1981; Kivanc \& Heelis, 1997; Basu et al., 1998; Carlson, 2012). During the solar maximum, the background electron density is high, and therefore, a small perturbation of the background electron density $(\mathrm{Ne})$ would produce high $\Delta \mathrm{Ne}$ and hence give rise to increased scintillation activity (Aarons et al., 1981). The situation is opposite during the solar minimum because the same percentage of perturbations in the relative low electron density would result in lower $\Delta \mathrm{Ne}$ and thus lower scintillation levels. The same reasoning can be used to explain the decrease in the GPS phase scintillation occurrence rate from autumn equinox to winter solstice. As shown in Figure 4, the ionospheric density was high during equinoxes and low near winter solstice. ${ }^{1}$ The decrease in the background density accounts for the low occurrence rate of ionospheric scintillation in the middle of the winter period.

The conspicuous minimum in the summer months was observed in the amplitude scintillation at $250 \mathrm{MHz}$ by Aarons et al. (1981) and Basu et al. (1988). The echo occurrence of the SuperDARN radars was also found to minimize during summer (e.g. Ruohoniemi \& Greenwald, 1997; Ghezelbash et al., 2014). More recent scintillation studies also revealed a reduction of the GPS phase scintillations during local summer ( $\mathrm{Li}$ et al., 2010; Prikryl et al., 2015). It has been proposed and well accepted that the low scintillation activity during summer is due to the conducting $\mathrm{E}$ region which can short-circuit the power of the F region irregularities (e.g. Aarons et al., 1981; Vickrey \& Kelley, 1982; Basu et al., 1985). In Figure 2b, we see that the short-circuit effect is so effective that the high solar elevation angle always corresponds to the low scintillation occurrence rate. More importantly, the sunlight smears the cusp signature of the GPS phase scintillation around noon, while the cusp related processes appear as a very effective source for plasma irregularities and GPS phase scintillations in winter (Moen et al., 2012, 2013; Jin et al., 2015; Oksavik et al., 2015).

\footnotetext{
${ }^{1}$ This is true except for the midnight $\mathrm{NmF} 2$ during the period from October 2014 to February 2015, when the midnight NmF2 decreased from October 2014 to February 2015.
} 


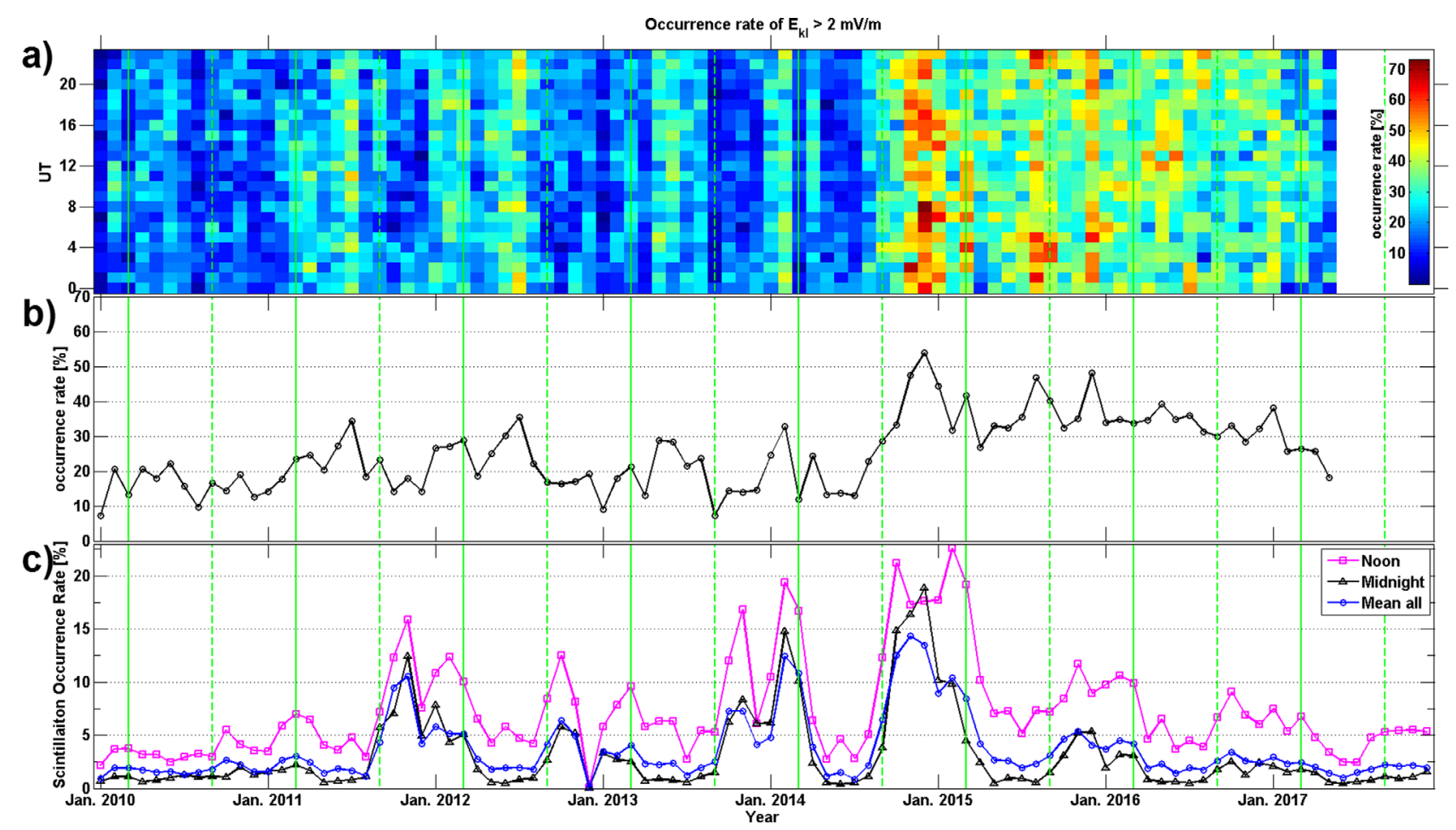

Fig. 5. (a) Diurnal and seasonal variations of the Kan-Lee electric field $\left(E_{\mathrm{KL}}=\mathrm{VB}_{\mathrm{T}} \sin ^{2}\left(\theta_{\mathrm{c}} / 2\right)\right.$. The data are divided into bins defined by $1 \mathrm{~h}$ in UT and by 1 month. (b) Mean occurrence rate of the $E_{\mathrm{KL}}>2 \mathrm{mV} / \mathrm{m}$ over all UT. (c) The occurrence rate of the GPS phase scintillation (same as Fig. 2c). The vertical green solid and dashed lines show the spring and autumn equinoxes, respectively.

More recently, Spicher et al. (2017) studied the seasonal distribution of the large-scale plasma structures in the polar cap (i.e. polar cap patches) by using Swarm satellites. They found a clear seasonal dependence of the polar cap patch occurrence, which maximizes during local winter and almost disappears during local summer in the Northern hemisphere. In summer, the maintenance of the background electron density in the polar cap by sunlight and the enhanced loss by recombination due to the chemical composition change in the thermosphere make it difficult to produce large scale density gradients such as polar cap patches (e.g. Schunk \& Sojka, 1987; Wood \& Pryse, 2010). Density gradients associated with polar cap patches are important free energy source for the production of small-scale plasma irregularities and hence the GPS scintillations in the polar ionosphere. The lack of large-scale electron density structures, such as polar cap patches, is another reason for a much reduced scintillation activity during summer, which we observe in this study.

We therefore explain the seasonal variations of the GPS phase scintillation to be the combined result of the sunlit E region ionosphere and the semiannual variation of the ionospheric electron density as well as the seasonal variation of polar cap patch occurrences.

\subsection{Solar wind forcing on the GPS phase scintillations}

While the solar cycle and seasonal variations of the background ionospheric electron density can explain the solar cycle and seasonal variations of the GPS phase scintillations, there are other factors, which may contribute to these variations.
One of them is the solar wind forcing. The Russel-McPherron (R-M) effect is often used to explain the semiannual variation of the geomagnetic activity which tends to be higher around the equinoxes than around solstices (Russell \& McPherron, 1973). The R-M effect arises from the semiannual variation of the difference between the geocentric solar ecliptic (GSE) and GSM coordinates (Russell \& McPherron, 1973; Zhao \& Zong, 2012; Lockwood et al., 2016, and references therein). This may also affect the seasonal variation of the GPS phase scintillations, since the high latitude ionosphere is directly affected by the solar wind.

In the following, we present results of the solar wind forcing in terms of the solar wind-magnetosphere coupling function with the focus on the seasonal variation. From several available coupling functions (see e.g. Newell et al., 2007), we choose the Kan-Lee electric field $E_{\mathrm{KL}}$ (see Sect. 2.3 for more details). However, this particular choice does not impact our results, as they do not seem to be sensitive to any coupling function.

Figure $5 \mathrm{a}$ shows the occurrence rate of $\mathrm{E}_{\mathrm{KL}}>2 \mathrm{mV} / \mathrm{m}$ between January 2010 and May 2017. Its variation with the solar cycle variation is clear: the occurrence rate of $E_{\mathrm{KL}}>2 \mathrm{mV} / \mathrm{m}$ is generally high during the declining phase of the solar cycle (after September 2014). When it comes to the R-M effect, the result for the coupling function does not show the predominant impact during equinoxes, in contrast to the findings by Zhao \& Zong (2012). The occurrence rate of high Kan-Lee electric field is very irregular and high values can appear at all seasons: in summers of 2011, 2012, and 2013; in the winter from 2014 to 2015; in springs of 2011, 2012, and 2015; in the autumn of 2015. The coupling function 
does not show any clear diurnal variations (i.e. variations with UT), neither. We therefore conclude that the R-M effect is unlikely to be the main cause of the seasonal variations of the GPS phase scintillation occurrence rate. More detailed discussion of the R-M effect is out of the scope of this paper, and in the following, we only compare the high values of $E_{\mathrm{KL}}$ to the scintillation occurrence rate.

Figure $5 \mathrm{~b}$ shows the mean occurrence rate of the $E_{\mathrm{KL}}>2 \mathrm{mV} / \mathrm{m}$ over all UT. The occurrence rate was high after September 2014, and it also shows local peaks in November 2011, July 2012, and May 2013 in accordance with the monthly sunspot number in Figure 2a. Figure $5 \mathrm{c}$ is reproduced from Figure $2 \mathrm{c}$ for an easy comparison with the scintillation occurrence rate. From Figure $5 \mathrm{~b}$ and $\mathrm{c}$ it follows that when the occurrence rate of $E_{\mathrm{KL}}>2 \mathrm{mV} / \mathrm{m}$ is high in the summers of 2011, 2012, and 2015, the occurrence rate of the GPS phase scintillation is indeed enhanced, but it is still lower than the phase scintillation occurrence rate in winter. However, when the occurrence rate of $E_{\mathrm{KL}}>2 \mathrm{mV} / \mathrm{m}$ is high in the winter of 2014-2015, the enhancement of the scintillation occurrence rate is the most pronounced and reaches the highest level in the solar cycle 24 . This suggests that the favoring IMF and solar wind conditions could indeed enhance the GPS phase scintillation activity in the high latitude ionosphere both in summer and winter. However, the solar wind forcing is strongly modulated by the sunlight condition, such that the strongest impact of the solar wind forcing takes place near local winter, when there is not much sunlight.

\section{Summary}

In this work, we have studied the solar cycle and seasonal variations of the GPS phase scintillation from the GPS scintillation receiver at Ny-Ålesund $\left(76.6^{\circ} \mathrm{MLAT}\right)$. The GPS data from $\mathrm{Ny}$-Ålesund cover a latitudinal range of more than $10^{\circ}$ (ranging $70^{\circ}-82^{\circ} \mathrm{MLAT}$ ). Ny-Ålesund is particularly well situated to observe scintillations associated with the cusp/polar cap dynamics on the dayside. At night the station is located in the polar cap for most of the time except during the expansion phase of substorms when it is exposed to nightside auroras.

The main findings can be summarized and explained as follows:

1. The GPS phase scintillation shows a clear solar cycle variation: demonstrating higher scintillation occurrence rate during the solar maximum and lower scintillation occurrence rate during the solar minimum. The GPS phase scintillation depends on absolute fluctuations of the electron density $(\Delta \mathrm{Ne})$ rather than the relative density fluctuations $(\Delta \mathrm{Ne} / \mathrm{Ne})$ (Aarons et al., 1981; Kivanc \& Heelis, 1997; Basu et al., 1998; Carlson, 2012), and the production term of irregularities links directly to the plasma density at $\mathrm{F} 2$ region $(\mathrm{NmF} 2)$, which depends on solar cycle and season.

2. The GPS phase scintillation presents clear seasonal variations: the scintillation activity is very low during local summer and high during local winter. This sharp contrast is much clearer during the solar maximum. The GPS scintillation is controlled by the ratio between the production and decay of irregularity power. The decay of the $\mathrm{F}$ region ionospheric irregularities depends on the E-region conductivity which is regulated by the solar activity and solar zenith angle (Moen \& Brekke, 1993). High E-region conductivity in summer will efficiently drain the irregularities that otherwise would persist. Furthermore, we note a local minimum in the scintillation occurrence near the winter solstice, which corresponds to the local minimum in $\mathrm{NmF} 2$ around the winter solstice.

3. In summer, the noon time scintillation occurrence is very low, and the nightside polar cap is void of scintillations. Plasma irregularities will not develop in summer since plasma gradients will be efficiently short-circuited by the highly conducting E-region.

4. The scintillation occurrence rate is generally highest around the magnetic noon except during the solar maximum when the nightside scintillation occurrence rate becomes comparable to that on the dayside. There are at least two apparent components in the explanation for the high occurrence rate at night. Firstly, during solar maximum there are higher substorm activity and poleward expansions into the field of view through which data has been recorded, and secondly, at night the NmF2 values of the plasma around Svalbard are transported from the American sector during daytime and they are highest during solar maximum.

5. The scintillation region around noon migrates equatorward from autumn equinox to winter solstice and retreats poleward from winter solstice to spring equinox in the magnetic latitude range of $74^{\circ}-80^{\circ}$. The seasonal movement of the noontime scintillation region resembles what has been revealed by tracking the cusp location using particle data from DMSP satellites (Newell \& Meng, 1989). This further strengthens the conclusion by Jin et al. (2015) that cusp auroral region is the predominant scintillation region in the dayside high-latitude ionosphere.

6. The background electron density during equinoxes exhibits a clear diurnal variation with one peak around magnetic noon, whilst the winter ionosphere shows two peaks, one around noon and one around midnight. The pronounced peak around midnight is due to the transport of plasma from the American sector across the polar cap (from day to night) (Moen et al., 2008).

7. The R-M effect is not likely to be the dominant cause of the seasonal variation of the GPS phase scintillation at high latitudes. However, the solar wind forcing indeed modulates the scintillation activity, and the strongest impact is in winter when the decay due to the E-region coupling is lowest.

Acknowledgements. The authors thank the Norwegian Polar Research Institute at $\mathrm{Ny}$-Ålesund for assisting us with the GPS receiver in Ny-Ålesund, Bjørn Lybekk and Espen Trondsen for the instrument operations. The IMF data are provided by the NASA OMNIWeb service (http://omniweb. gsfc.nasagov). The authors thank Michael Rietveld for providing the dynasonde data. Data from the EISCAT dynasonde can be obtained from http://www.eiscat.uit.no/dynasond. html. Sunspot data are from the World Data Center SILSO, 
Royal Observatory of Belgium, Brussels (http://www.sidc.be/ silso/). This research is a part of the 4DSpace Strategic Research Initiative at the University of Oslo. The work has been supported by the Research Council of Norway grants 275653 and 267408 . Yaqi Jin is partly supported by the Swarm Data, Innovation, and Science Cluster (DISC) project found by ESA. Yaqi Jin wishes to thank the International Space Science Institute in Beijing (ISSI-BJ) for supporting and hosting the meetings of the International Team on "Multiple-instrument observations and simulations of the dynamical processes associated with polar cap patches/aurora and their associated scintillations", during which the discussions leading/contributing to this publication were initiated/ held. The editor thanks two anonymous referees for their assistance in evaluating this paper.

\section{References}

Aarons J. 1982. Global Morphology of Ionospheric Scintillations. Proc. IEEE. 70(4): 360-378.

Aarons J, Mullen JP, Whitney HE, Johnson AL, Weber EJ. 1981. Uhf Scintillation Activity over Polar Latitudes. Geophys Res Lett 8(3): 277-280. DOI: 10.1029/GL008i003p00277.

Aarons J, Lin B, Mendillo M, Liou K, Codrescu M. 2000. Global Positioning System phase fluctuations and ultraviolet images from the polar satellite. J Geophys Res Space 105(A3): 5201-5213. DOI: $10.1029 / 1999$ ja900409.

Alfonsi L, Spogli L, De Franceschi G, Romano V, Aquino M, Dodson A, Mitchell CN. 2011. Bipolar climatology of GPS ionospheric scintillation at solar minimum. Radio Sci 46, (RS0D05). DOI: 10.1029/2010RS004571.

Alfonsi L, Spogli L, Pezzopane M, Romano V, Zuccheretti E, De Franceschi G, Cabrera MA, Ezquer RG. 2013. Comparative analysis of spread-F signature and GPS scintillation occurrences at Tucuman, Argentina. J Geophys Res-Space. 118(7): 4483-4502. DOI: 10.1002 /jgra.50378.

Basu S, Mackenzie E, Basu S. 1988. Ionospheric Constraints on Vhf Uhf Communications Links during Solar Maximum and Minimum Periods. Radio Sci 23(3): 363-378. DOI: 10.1029/ RS023i003p00363.

Basu S, Basu S, MacKenzie E, Whitney HE. 1985. Morphology of phase and intensity scintillations in the auroral oval and polar cap. Radio Sci 20(3): 347-356. DOI: 10.1029/RS020i003p00347.

Basu S, Groves KM, Basu S, Sultan PJ. 2002. Specification and forecasting of scintillations in communication/navigation links: current status and future plans. J Atmos Sol-Terr Phys 64(16): 1745-1754. DOI: 10.1016/S1364-6826(02)00124-4.

Basu S, MacKenzie E, Costa E, Fougere P, Carlson H, Whitney H. 1987. $250 \mathrm{MHz} / \mathrm{GHz}$ scintillation parameters in the equatorial, polar, and auroral environments. IEEE J Sel Areas Commun 5(2): $102-115$.

Basu S, Basu S, Mackenzie E, Coley WR, Sharber JR, Hoegy WR. 1990. Plasma Structuring by the Gradient Drift Instability at High-Latitudes and Comparison with Velocity Shear Driven Processes. J Geophys Res Space 95(A6): 7799-7818. DOI: 10.1029/JA095iA06p07799.

Basu S, Basu S, Costa E, Bryant C, Valladares C, Livingston R. 1991. Interplanetary magnetic field control of drifts and anisotropy of high-latitude irregularities. Radio Sci 26(4): 1079-1103. DOI: 10.1029/91RS00586.
Basu S, Weber EJ, Bullett TW, Keskinen MJ, MacKenzie E, Doherty P, Sheehan R, Kuenzler H, Ning P, Bongiolatti J. 1998. Characteristics of plasma structuring in the cusp/cleft region at Svalbard. Radio Sci 33(6): 1885-1899. DOI: 10.1029/98RS01597.

Breed A, Goodwin G. 1997. Ionospheric slab thickness and total electron content determined in Australia. Radio Sci 32(4): 1635-1643. DOI: 10.1029/97RS00454.

Cai H, Ma S, Fan Y, Liu Y, Schlegel K. 2008. Climatological features of electron density in the polar ionosphere from longterm observations of EISCAT/ESR radar. Ann Geophys 25: 2561-2569.

Carlson HC. 2012. Sharpening our thinking about polar cap ionospheric patch morphology, research, and mitigation techniques. Radio Sci 47(RS0L21), DOI: 10.1029/2011RS004946.

Carlson HC, Oksavik K, Moen J. 2008. On a new process for cusp irregularity production. Ann Geophys Germany 26(9): 2871-2885.

Carlson HC, Pedersen T, Basu S, Keskinen M, Moen J. 2007. Case for a new process, not mechanism, for cusp irregularity production. J Geophys Res Space 112(A11304), DOI: 10.1029/2007JA012384.

Clausen LBN, Moen JI, Hosokawa K, Holmes JM. 2016. GPS scintillations in the high latitudes during periods of dayside and nightside reconnection. J Geophys Res Space 121(4): 3293-3309. DOI: $10.1002 / 2015$ ja022199.

Ghezelbash M, Koustov A, Themens D, Jayachandran P. 2014. Seasonal and diurnal variations of PolarDARN $\mathrm{F}$ region echo occurrence in the polar cap and their causes. J Geophys Res Space Phys 119(12): 10426-10439. DOI: 10.1002/2014JA020726.

Hathaway D. 2015. The solar cycle. Living Rev Solar Phys 12: 1rsp2015-4. DOI: 10.1007/lrsp-2015-4.

Hey JS, Parsons SJ, Phillips JW. 1946. Fluctuations in cosmic radiation at radio-frequencies. Nature 158(4007): 234-34.

Holzworth R, Meng CI. 1975. Mathematical representation of the auroral oval. Geophys Res Lett 2(9): 377-380. DOI: 10.1029/ GL002i009p00377.

Jin Y, Moen JI, Miloch WJ. 2014. GPS scintillation effects associated with polar cap patches and substorm auroral activity: direct comparison. J Space Weather Space 4(A23). DOI: $10.1051 /$ swsc/2014019.

Jin Y, Moen JI, Miloch WJ. 2015. On the collocation of the cusp aurora and the GPS phase scintillation: A statistical study. $J$ Geophys Res Space edited 9176-9191. DOI: 10.1002/ 2015JA021449.

Jin Y, Moen JI, Miloch WJ, Clausen LBN, Oksavik K. 2016. Statistical study of the GNSS phase scintillation associated with two types of auroral blobs. J Geophys Res-Space 121(5): 4679-4697. DOI: 10.1002/2016ja022613.

Jin Y, Moen JI, Oksavik K, Spicher A, Clausen LBN, Miloch WJ. 2017. GPS scintillations associated with cusp dynamics and polar cap patches. J Space Weather Space 7. DOI: 10.1051/swsc/2017022.

Kan J, Lee L. 1979. Energy coupling function and solar windmagnetosphere dynamo. Geophys Res Lett 6(7): 577-580.

Kelley MC, Vickrey JF, Carlson CW, Torbert R. 1982. On the Origin and Spatial Extent of High-Latitude F-Region Irregularities. $J$ Geophys Res-Space 87(Na6): 4469-4475. DOI: 10.1029/ JA087iA06p04469.

Keskinen MJ, Ossakow SL. 1983. Theories of High-Latitude Ionospheric Irregularities - a Review. Radio Sci 18(6): 1077 1091. DOI: 10.1029/RS018i006p01077.

Keskinen MJ, Mitchell HG, Fedder JA, Satyanarayana P, Zalesak ST, Huba JD. 1988. Nonlinear Evolution of the Kelvin-Helmholtz Instability in the High-Latitude Ionosphere. J Geophys Res: Space Phys 93(A1): 137-152. DOI: 10.1029/JA093iA01p00137. 
King JH, Papitashvili NE. 2005. Solar wind spatial scales in and comparisons of hourly Wind and ACE plasma and magnetic field data. J Geophys Res-Space 110(A2). DOI: 10.1029/2004JA010649.

Kintner PM, Ledvina BM, De Paula ER. 2007. GPS and ionospheric scintillations. Space Weather 5(9): DOI: 10.1029/2006sw000260.

Kivanc O, Heelis RA. 1997. Structures in ionospheric number density and velocity associated with polar cap ionization patches. $J$ Geophys Res Space 102(A1): 307-318.

Li G, Ning BQ, Ren ZP, Hu LH. 2010. Statistics of GPS ionospheric scintillation and irregularities over polar regions at solar minimum. GPS Solut 14(4): 331-341.

Lockwood M, Moen J, van Eyken AP, Davies JA, Oksavik K, McCrea IW. 2005. Motion of the dayside polar cap boundary during substorm cycles: I. Observations of pulses in the magnetopause reconnection rate. Ann Geophys Germany 23(11): 3495-3511.

Lockwood M, Owens MJ, Barnard LA, Bentley S, Scott CJ, Watt CE. 2016. On the origins and timescales of geoeffective IMF. Space Weather 14(6): 406-432.

Lorentzen DA, Shumilov N, Moen J. 2004. Drifting airglow patches in relation to tail reconnection. Geophys Res Lett 31(2), DOI: 10.1029/2003GL017785.

Milan S, Yeoman T, Lester M. 1998. The dayside auroral zone as a hard target for coherent HF radars. Geophys Res Lett 25(19): 3717-3720. DOI: 10.1029/98GL02781.

Mitchell CN, Alfonsi L, De Franceschi G, Lester M, Romano V, Wernik AW. 2005. GPS TEC and scintillation measurements from the polar ionosphere during the October 2003 storm. Geophys Res Lett 32(12), DOI: 10.1029/2004GL021644.

Moen J, Brekke A. 1993. The solar flux influence on quiet time conductances in the auroral ionosphere. Geophys Res Lett 20(10): 971-974.

Moen J, van Eyken AP, Carlson HC. 2001a. EISCAT Svalbard Radar observations of ionospheric plasma dynamics in relation to dayside auroral transients. J Geophys Res Space 106(A10): 21453-21461.

Moen J, Walker IK, Kersley L, Milan SE. 2002. On the generation of cusp HF backscatter irregularities. J Geophys Res-Space 107(A4).

Moen J, Gulbrandsen N, Lorentzen DA, Carlson HC. 2007. On the MLT distribution of F region polar cap patches at night. Geophys Res Lett 34(14).

Moen J, Hosokawa K, Gulbrandsen N, Clausen LBN. 2015. On the symmetry of ionospheric polar cap patch exits around magnetic midnight. J Geophys Res Space 120(9): 7785-7797. DOI: 10.1002/2014ja020914.

Moen J, Qiu XC, Carlson HC, Fujii R, McCrea IW. 2008. On the diurnal variability in F2-region plasma density above the EISCAT Svalbard radar. Ann Geophys Germany 26(8): 2427-2433.

Moen J, Oksavik K, Alfonsi L, Daabakk Y, Romano V, Spogli L. 2013. Space weather challenges of the polar cap ionosphere. $J$ Space Weather Space $\mathbf{3}$

Moen J, Carlson HC, Milan SE, Shumilov N, Lybekk B, Sandholt PE, Lester M. 2001b. On the collocation between dayside auroral activity and coherent HF radar backscatter. Ann Geophys-Atm Hydr 18(12): 1531-1549.

Moen J, Lockwood M, Oksavik K, Carlson HC, Denig WF, van Eyken AP, McCrea IW. 2004. The dynamics and relationships of precipitation, temperature and convection boundaries in the dayside auroral ionosphere. Ann Geophys Germany 22(6): 1973-1987.

Moen J, Oksavik K, Abe T, Lester M, Saito Y, Bekkeng TA, Jacobsen KS. 2012. First in-situ measurements of HF radar echoing targets. Geophys Res Lett 39.
Moen J, Carlson HC, Oksavik K, Nielsen CP, Pryse SE, Middleton HR, McCrea IW, Gallop P. 2006. EISCAT observations of plasma patches at sub-auroral cusp latitudes. Ann Geophys-Germany 24(9): 2363-2374.

Newell PT, Meng CI. 1989. Dipole Tilt Angle Effects on the Latitude of the Cusp and Cleft Low-Latitude Boundary-Layer. $J$ Geophys Res Space 94(A6): 6949-6953.

Newell PT, Meng CI, Sibeck DG, Lepping R. 1989. Some LowAltitude Cusp Dependencies on the Interplanetary MagneticField. J Geophys Res Space 94(A7): 8921-8927.

Newell PT, Sotirelis T, Liou K, Meng CI, Rich FJ. 2006. Cusp latitude and the optimal solar wind coupling function. $J$ Geophys Res Space 111(A9).

Newell PT, Sotirelis T, Liou K, Meng CI, Rich FJ. 2007. A nearly universal solar wind-magnetosphere coupling function inferred from 10 magnetospheric state variables. J Geophys Res Space 112(1).

Oksavik K, Moen J, Carlson HC. 2004. High-resolution observations of the small-scale flow pattern associated with a poleward moving auroral form in the cusp. Geophys Res Lett 31(11). DOI: 10.1029/ 2004GL019838.

Oksavik K, Moen JI, Rekaa EH, Carlson HC, Lester M. 2011. Reversed flow events in the cusp ionosphere detected by SuperDARN HF radars. J Geophys Res-Space 116. DOI: 10.1029/2011JA016788.

Oksavik K, Moen J, Lester M, Bekkeng TA, Bekkeng JK. 2012. In situ measurements of plasma irregularity growth in the cusp ionosphere. J Geophys Res-Space 117. DOI: 10.1029/ 2012JA017835.

Oksavik K, van der Meeren C, Lorentzen DA, Baddeley LJ, Moen J. 2015. Scintillation and loss of signal lock from poleward moving auroral forms in the cusp ionosphere. J Geophys Res-Space 120(10): 9161-9175. DOI: 10.1002/2015ja021528.

Oksavik K, Moen J, Carlson HC, Greenwald RA, Milan SE, Lester M, Denig WF, Barnes RJ. 2005. Multi-instrument mapping of the small-scale flow dynamics related to a cusp auroral transient Ann Geophys Germany 23(7): 2657-2670. DOI: 10.5194/angeo-232657-2005.

Prikryl P, Jayachandran PT, Mushini SC, Chadwick R. 2011. Climatology of GPS phase scintillation and HF radar backscatter for the high-latitude ionosphere under solar minimum conditions. Ann Geophys Germany 29(2): 377-392.

Prikryl P, Jayachandran PT, Mushini SC, Richardson IG. 2012. Toward the probabilistic forecasting of high-latitude GPS phase scintillation. Space Weather 10. DOI: 10.1029/2012SW000800.

Prikryl P, Jayachandran PT, Chadwick R, Kelly TD. 2015. Climatology of GPS phase scintillation at northern high latitudes for the period from 2008 to 2013. Ann Geophys Germany 33(5): 531545. DOI: 10.5194/angeo-33-531-2015.

Prikryl P, Jayachandran PT, Mushini SC, Pokhotelov D, MacDougall JW, Donovan E, Spanswick E, St Maurice JP. 2010. GPS TEC, scintillation and cycle slips observed at high latitudes during solar minimum. Ann Geophys-Germany 28(6): 1307-1316.

Priyadarshi S, Zhang QH, Ma YZ, Wang Y, Xing ZY. 2016. Observations and modeling of ionospheric scintillations at South Pole during six X-class solar flares in 2013. J Geophys Res Space Phys 121(6): 5737-5751. DOI: 10.1002/2016JA022833.

Rietveld M, Wright J, Zabotin N, Pitteway M. 2008. The Tromsø dynasonde. Polar Sci 2(1): 55-71.

Rinne Y, Moen J, Oksavik K, Carlson HC. 2007. Reversed flow events in the winter cusp ionosphere observed by the European Incoherent Scatter (EISCAT) Svalbard radar. J Geophys Res Space 112(10). DOI: 10.1029/2007JA012366. 
Rino CL. 1979. Power Law Phase Screen Model for Ionospheric Scintillation. 2. Strong Scatter. Radio Sci 14(6): 1147-1155. DOI: 10.1029/RS014i006p01135.

Rino CL, Livingston RC, Tsunoda RT, Robinson RM, Vickrey JF, Senior C, Cousins MD, Owen J, Klobuchar JA. 1983. Recent Studies of the Structure and Morphology of Auroral-Zone FRegion Irregularities. Radio Sci 18(6): 1167-1180. DOI: 10.1029/ RS018i006p01167.

Ruohoniemi J, Greenwald R. 1997. Rates of scattering occurrence in routine $\mathrm{HF}$ radar observations during solar cycle maximum. Radio Sci 32(3): 1051-1070.

Russell C, McPherron R. 1973. Semiannual variation of geomagnetic activity. J Geophys Res 78(1): 92-108.

Sandholt PE, Farrugia CJ, Moen J, Noraberg O, Lybekk B, Sten T, Hansen T. 1998. A classification of dayside auroral forms and activities as a function of interplanetary magnetic field orientation. $J$ Geophys Res-Space 103(A10): 23325-23345. DOI: 10.1029/98JA02156.

Schunk RW, Sojka JJ. 1987. A theoretical study of the lifetime and transport of large ionospheric density structures. J Geophys Res Space Phys 92(11): 12343-12351.

Spicher A, Clausen LBN, Miloch WJ, Lofstad V, Jin Y, Moen JI. 2017. Interhemispheric study of polar cap patch occurrence based on Swarm in situ data. J Geophys Res-Space 122(3): 3837-3851. DOI: $10.1002 / 2016 j a 023750$.

Spicher A, Cameron T, Grono EM, Yakymenko KN, Buchert SC, Clausen LBN, Knudsen DJ, McWilliams KA, Moen JI. 2015. Observation of polar cap patches and calculation of gradient drift instability growth times: A Swarm case study. Geophys Res Lett 42(2): 201-206. DOI: 10.1002/2014g1062590.

Spogli L, Alfonsi L, De Franceschi G, Romano V, Aquino MHO, Dodson A. 2009. Climatology of GPS ionospheric scintillations over high and mid-latitude European regions. Ann GeophysGermany 27(9): 3429-3437.

Spogli L, Alfonsi L, Romano V, De Franceschi G, Monico JFG, Shimabukuro MH, Bougard B, Aquino M. 2013. Assessing the GNSS scintillation climate over Brazil under increasing solar activity. J Atmos Sol-Terr Phys 105: 199-206.

Themens DR, Jayachandran P. 2016. Solar activity variability in the IRI at high latitudes: Comparisons with GPS total electron content. J Geophys Res Space Phys 121(4): 3793-3807.

Tsurutani BT, Gonzalez WD, Gonzalez AL, Guarnieri FL, Gopalswamy N, Grande M, Kamide Y, Kasahara Y, Lu G, Mann I. 2006. Corotating solar wind streams and recurrent geomagnetic activity: A review. J Geophys Res Space Phys 111(A7).

van der Meeren C, Oksavik K, Lorentzen D, Moen JI, Romano V. 2014. GPS scintillation and irregularities at the front of an ionization tongue in the nightside polar ionosphere. $J$ Geophys Res Space Phys 119(10): 8624-8636. DOI: 10.1002/2014JA020114. van der Meeren C, Oksavik K, Lorentzen DA, Rietveld MT, Clausen LB. 2015. Severe and localized GNSS scintillation at the poleward edge of the nightside auroral oval during intense substorm aurora. $J$ Geophys Res Space Phys 120(12): 10607-10621. DOI: 10.1002/ 2015JA021819.

Van Dierendonck AJ, Klobuchar J, Hua Q. 1993. Ionospheric Scintillation Monitoring Using Commercial Single Frequency C/ A Code Receivers. Paper presented at Proceedings of the 6th International Technical Meeting of the Satellite Division of The Institute of Navigation (ION GPS 1993), Salt Lake City, UT, September 22-24, 1993.

Vickrey JF, Kelley MC. 1982. The Effects of a Conducting E-Layer on Classical F-Region Cross-Field Plasma-Diffusion. $J$ Geophys Res Space 87(Na6): 4461-4468. DOI: 10.1029/JA087iA06p04461.

Wang Y, Zhang QH, Jayachandran P, Lockwood M, Zhang SR, Moen J, Xing ZY, Ma YZ, Lester M. 2016. A comparison between large-scale irregularities and scintillations in the polar ionosphere. Geophys Res Lett 43(10): 4790-4798. DOI: 10.1002/ 2016GL069230.

Weber EJ, Klobuchar JA, Buchau J, Carlson HC, Livingston RC, Delabeaujardiere O, Mccready M, Moore JG, Bishop GJ. 1986. Polar cap-F layer patches - structure and dynamics. J Geophys Res Space 91(11): 2121-2129. DOI: 10.1029/JA091iA11p12121.

Wernik AW, Secan JA, Fremouw EJ. 2003. Ionospheric irregularities and scintillation. Space Weather 31(4), 971-981. DOI: 10.1016/ S0273-1177(02)00795-0.

Wood A, Pryse S. 2010. Seasonal influence on polar cap patches in the high-latitude nightside ionosphere. J Geophys Res Space Phys 115(7).

Yeh KC, Liu CH. 1982. Radiowave scintillations in the ionosphere. Proc IEEE 70(4): 324-360.

Zabotin N, Wright J, Zhbankov G. 2006. NeXtYZ: Threedimensional electron density inversion for dynasonde ionograms. Radio Sci 41(6).

Zhang QH, Ma YZ, Jayachandran P, Moen J, Lockwood M, Zhang YL, Foster J, Zhang SR, Wang Y, Themens D. 2017. Polar cap hot patches: Enhanced density structures different from the classical patches in the ionosphere. Geophys Res Lett 44(16): 8159-8167. DOI: $10.1002 / 2017$ GL073439.

Zhang QH, et al. 2013. Direct Observations of the Evolution of Polar Cap Ionization Patches. Science 339(6127): 1597-1600.

Zhao H, Zong QG. 2012. Seasonal and diurnal variation of geomagnetic activity: Russell-McPherron effect during different IMF polarity and/or extreme solar wind conditions. J Geophys Res Space Phys 117(11).

Zou L, Rishbeth H, Müller-Wodarg I, Aylward A, Millward G, Fuller-Rowell T, Idenden D, Moffett R. 2000. Annual and semiannual variations in the ionospheric F2-layer. I. Modelling. Ann Geophys 18: 927-944.

Cite this article as: Jin Y, Miloch W, Moen J \& Clausen L 2018. Solar cycle and seasonal variations of the GPS phase scintillation at high latitudes. J. Space Weather Space Clim. 8, A48. 